\title{
Developmental Systems Theory
}

\author{
Paul E Griffiths, University of Sydney, Sydney, NSW, Australia \\ Adam Hochman, Macquarie University, Sydney, NSW, Australia \\ Based in part on the previous version of this eLS article 'Developmental \\ Systems Theory' (2001) by Paul E Griffiths.
}

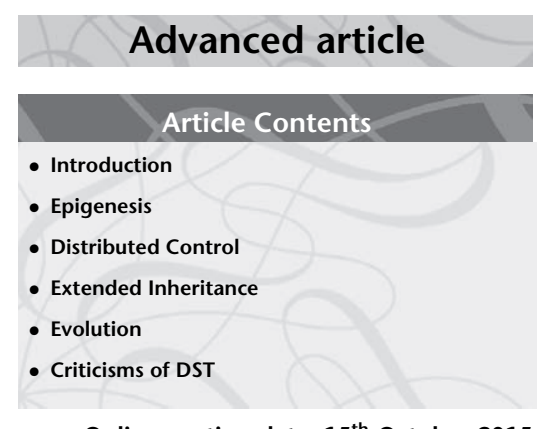

Online posting date: $15^{\text {th }}$ October 2015

\begin{abstract}
Developmental systems theory (DST) is a wholeheartedly epigenetic approach to development, inheritance and evolution. The developmental system of an organism is the entire matrix of resources that are needed to reproduce the life cycle. The range of developmental resources that are properly described as being inherited, and which are subject to natural selection, is far wider than has traditionally been allowed. Evolution acts on this extended set of developmental resources. From a developmental systems perspective, development does not proceed according to a preformed plan; what is inherited is much more than DNA; and evolution is change not only in gene frequencies, but in entire developmental systems.
\end{abstract}

\section{Introduction}

The phrase 'developmental system' was introduced by the biologist Conrad Waddington to refer to the dynamical system constituted when the totality of the genes in an organism, and their products, interacts with one another in development (Waddington, 1952). The developmental system is the locus of the epigenetic processes by which the genotype gives rise to a phenotype (Waddington, 1940). Waddington contrasted classical genetic approaches, which merely correlate genotype and phenotype, with his own epigenetic approach, which sought to understand the mechanism connecting the two (Waddington, 2012 [1942], p. 10). The term 'epigenesis' originated in the seventeenth century and refers to the view that the embryo comes into existence during development, rather than existing in miniature as suggested by the opposing preformationist theory. The developmental psychobiologist Gilbert Gottlieb advanced a more radically epigenetic

\footnotetext{
eLS subject area: Bioethics \& Philosophy

How to cite:

Griffiths, Paul E and Hochman, Adam (October 2015)

Developmental Systems Theory. In: eLS. John Wiley \& Sons,

Ltd: Chichester.

DOI: $10.1002 / 9780470015902 . a 0003452 . p u b 2$
}

perspective than Waddington, distinguishing between what he termed 'predetermined' and 'probabilistic' epigenesis (Gottlieb, 1970). In predetermined epigenesis, the contents of the fertilised egg largely determine the course of development, and the environment provides mainly nonspecific support for the unfolding of the epigenetic process. In probabilistic epigenesis, the course of development depends on the interaction between each stage in development and environmental factors at that stage. Research into this kind of sensitive dependence of development on the environment is characteristic of the developmental psychobiology research tradition and embodies what Gottlieb came to call the 'developmental psychobiological systems view' (Gottlieb, 2001). See also: Epigenetic Variation in Humans; Epigenetic Factors and Chromosome Organization; Baer, Karl Ernst von

Developmental systems theory also has roots in a tradition of scepticism about the innate/acquired distinction in American comparative psychology (Johnston, 2001). This culminated in an influential critique by Daniel Lehrman, which set the agenda for much research in developmental psychobiology (Lehrman, 1953). Lehrman's research, like Gottlieb's, set out to document the dependence of development on very specific interactions between the developing organism and its environment. Behaviour that had previously been labelled 'innate' would turn out to depend on environmental influences in nonobvious and sometimes surprising ways. To label behaviour as 'innate' or 'instinctive' is misleading because, as psychologist Zing Yang Kuo argued, it raises the further question, 'How are our instincts acquired?' (Kuo, 1922).

Susan Oyama added an important element to development systems theory with her book The Ontogeny of Information: Developmental Systems and Evolution (Oyama, 1985). The ideas of genetic information and genetic programs have provided important theoretical support for the idea that epigenetic processes are predetermined by the contents of the fertilised egg. Oyama argued that the phenotypic significance of a single developmental factor, genetic or otherwise, is a function of its role in the larger developmental system. She analysed how the idea of genetic information has been used to minimise the impact of accepting that all phenotypes develop through the constructive interaction of genes and other developmental resources, typically lumped together as 'environmental'. See also: Geneticisation: Concept; Geneticization: Debates and Controversies

The phrase 'developmental systems theory' was introduced by Donald Ford and Richard Lerner as the title of a book setting 
out a systematic research agenda for developmental psychology which incorporated many of the themes introduced above (Ford and Lerner, 1992). It was soon applied to Oyama's critique of the idea of genetic information (Griffiths and Gray, 1994), and in many areas of biology the phrase is primarily associated with this idea (a more detailed history developmental systems theory can be found in Griffiths and Tabery, 2013).

\section{Epigenesis}

It is a truism that all traits are produced by the interaction of genetic and environmental factors (Kitcher, 2001). DST goes beyond this conventional interactionism and aims at a truly epigenetic view of development in the sense described above. The life cycle of an organism is not prefigured in a genetic program, but is constructed at each stage in development through the interaction of organism and environment. Even the production of functional products from a DNA sequence requires an interaction between the current state of the genome and the cellular environment, both of which are products of earlier stages in development, a view that has been termed 'molecular epigenesis' (Stotz, 2006).

The acceptance that every trait depends on both genes and environment sometimes seems to amount to no more than admitting that every organism must have some environment and some genes. With that out of the way, the real business of settling what is due to nature and what to nurture can continue. A whole range of methods, from the study of twins to Genome Wide Association Studies (GWAS), can be used to estimate the correlation between genes and phenotype in a population. The stronger the correlation, the more the genes are said to be responsible for the trait. However, these correlations are not legitimate measures of causal responsibility; nor do they indicate how much a trait can be modified by environmental changes. Heritability measures can be increased by choosing a population who all live in similar environments. Conversely, heritability can be reduced by choosing a population of genetically similar organisms. Neither of these manipulations can reasonably be supposed to alter the relative causal role of genes and environment in the growth of the trait and neither has any bearing on how easy it is to modify the trait by manipulating nongenetic factors. So heritability measures are a very bad way to measure 'how genetic' a trait is, or how much it is due to nature rather than nurture. See also: Genome-Wide Association Studies; Nature/Nurture - A Philosophical Analysis; Genotype-Phenotype Relationships; Twinning; Twin Studies; Complex Multifactorial Genetic Diseases

The idea that the genome contains a program for development makes it hard to give due weight to context sensitivity and developmental contingency. As long as the DNA is thought of as containing information about developmental outcomes, it will seem sensible to inquire whether outcomes occur because they are represented in the DNA, or whether they are due to other, merely material causal influences. Once an outcome is seen as an expression of the genetic information that controls development, it acquires a special status. It represents what the organism is 'meant to be', and deviations from it are misrepresentations of the true nature of the organism (Linquist et al., 2011). From this perspective, the effect of context on development appears as interference with the basic pattern of biological causation. For DST, however, context sensitivity is what should be expected from the nature of development. Developmental outcomes are not preformed or represented in the fertilised egg, but emerge through the interaction of each stage of the developing organism with its surroundings. See also: Evolutionary Developmental Biology: Developmental Bias and Constraint; Environmental Heterogeneity: Temporal and Spatial

A key way in which DST tries to improve on the truism that there is an interaction between genes and environment is by rejecting that dichotomy itself as inadequate. There are many influences on development and many ways to group the interactants together. The distinction between genes and every other causal factor in development ('environment') is just one of many possible distinctions. Moreover, there is a fundamental 'parity' (see Box 1) between genes and other causes. The roles classically played by DNA and RNA sequences are sometimes filled by other developmental causes. For example, DNA-coding sequences determine the order of amino acids in proteins, but environmental signals can also determine this order by causing alternative splicing or editing of an mRNA transcript. Conversely, some DNA sequences play roles more usually associated with a nongenetic factor. For example, chromatin insulator regions of DNA play a role in the facultative modification of chromatin to regulate gene expression. Their role is more like the role of epigenetic mechanisms such as DNA methylation than the role played by coding regions of the DNA. See also: Imprinting (Mammals); Genetics, Reductionism and Autopoiesis

Another way in which DST tries to move beyond conventional 'interactionism' is by recognising that development is a process of dynamic interaction (Ford and Lerner, 1992). It is dynamic in the sense that development at each stage builds on the results of development at an earlier stage. The components built by interaction at one stage of development are the components which do the interacting at a later stage: 'The interaction out of which the organism develops is not one, as is so often said, between heredity and environment. It is between organism and environment! And the organism is different at each stage of its development' (Lehrman, 1953, p. 345, emphasis in original). Not only the organism but also the environment changes as a result of development. For example, male sexual development in the rat depends on differential licking of the genital area of male and female pups by the mother. However, her response to male pups depends on differences in their urine, which are the result of earlier processes of sexual differentiation (Moore, 1992). The presence of this environmental influence is a feed forward from earlier development in the pup itself. See also: History of Developmental Biology

\section{Distributed Control}

As an epigenetic account of development, DST rejects the widespread idea in contemporary biology that development is guided by information contained within a 'genetic program' (see Box 2). According to Ernst Mayr, 'genes are merely the units of the genetic program that governs the complicated process of development, ultimately resulting in the phenotypic character' 


\section{Box 1 The Parity Thesis}

Susan Oyama (2000a, pp. 200-203) called for parity of reasoning when genetic and other causes play similar roles in development. The 'parity thesis' is the claim that if some role is alleged to be unique to nucleic acids and to justify relegating nongenetic factors to a secondary role in explaining development, it will turn out on closer examination that this role is not unique to nucleic acids, but can be played by other factors. Parity is often referred to as 'causal democracy' (Kitcher, 2001), although Oyama herself rejects this label (Oyama, 2000b). Causal democracy is the principle that when an effect depends on many causes, it is legitimate to investigate the significance of any of those causes, and in particular, that nongenetic causes of development are not a priori less significant than genetic causes (Kitcher, 2001, p. 290). Both parity and causal democracy are alleged by critics to amount to a refusal to accept that any cause can ever be more significant or explanatory than another (e.g. Waters, 2007, Weber, 2006). Advocates of DST have made repeated attempts to rebut this charge (Griffiths and Gray, 2005; Griffiths and Knight, 1998; Oyama, 2000b, Griffiths, in press).

\section{Box 2 The Phylogeny Fallacy}

In 1990, Robert Lickliter and Thomas Berry identified the phylogeny fallacy: the conflation of proximate and evolutionary explanation (Hochman, 2012). The phylogeny fallacy is committed when an evolutionary 'why' answer is given to a proximate 'how' question. Explanations that appeal to 'genetic programs' are often instances of the phylogeny fallacy because they tend be evolutionary explanations for why the trait should be considered an adaptation, rather than proximate explanations concerning the mechanisms underlying that trait. The 'genetic program' concept is deduced from the modern synthesis, it is not an object of empirical investigation. From a DST perspective, assuming adaptations to be preprogrammed into genes is a bad empirical bet.

(Mayr, 1970, p. 163). This has been the consensus view ondevelopment since the modern synthesis. The most obvious way to defend talk of genetic programs and genetic information is to argue that these concepts are intended in some unproblematic sense to be related to information theory. Two coherent accounts of 'genetic information' can be found in the literature: a causal account and an intentional account (Sterelny and Griffiths, 1999). Yet, neither account can sustain the view that genes can be privileged as uniquely informational, or as the locus of a programme-controlling development.

The causal account of information stems from mathematical communication theory. According to this account, information flows through a channel connecting a sender to a receiver. There is a channel between two systems whenever observing the state of the receiver reduces uncertainty about the state of the sender. Channel conditions are other factors that must be in place to connect the sender and receiver. The channel that connects the ignition key to an engine has many channel conditions, including the spark plugs, rotor and ignition coil. However, while it seems natural to treat turning the key as a 'signal' for the engine to start, and the spark plugs, rotor and ignition coil as channel conditions, this is a product of our position in the system, not a fact about the world. For an auto mechanic, the ignition is often not the signal source. When testing the ignition coil, for instance, it becomes the signal source, rather than a channel condition. Fundamental to information theory is the fact that the role of signal source and channel conditions can be switched. On the causal account, information is simply covariation.

The attempt to privilege genes as uniquely informational on the causal account of information fails, as this account creates parity between DNA and other resources that affect development. By keeping a matrix of developmental resources constant, genes can covary with, and therefore give us information about, phenotypes. However, keep genes constant, and change another developmental factor, and that factor will give us information about the phenotype: 'there is no difficulty in saying that a gene carries information about adult form; an individual with the gene for achondroplasia will have short arms and legs. But we can equally well say that a baby's environment carries information about growth; if it is malnourished, it will be underweight' (Maynard Smith, 2000, p. 189). What was previously considered a channel condition now provides the source of information. 'Information talk' is thus equally applicable to nongenetic causal factors in development, according to this account of information.

Maynard Smith (2000) suggested that the causal account of information does not capture what is really meant when biologists talk about genetic information. According to Maynard Smith, biologists use information in a semantic rather than a causal sense - a gene has an intended meaning rather than just causal consequences. This allowed him to accept that genes are not the only developmental causes and not the only factors that are inherited, while maintaining a fundamental asymmetry between 
genes and other factors. Maynard Smith proposed a 'teleosemantic' account of information in biology: a gene contains intentional information about the phenotype that it has been selected to produce. The selective retention of advantageous genetic variation over time produces a 'genetic program' in which genes generate the developmental outcomes that they were selected for.

The problem with this view is that nongenetic developmental factors have selective histories of their own, and as such they too contain information about the developmental outcomes in virtue of which they were selected. The zygote, the first cell formed when a new organism is produced by means of sexual reproduction, is a matrix of inherited structures, including basal bodies, microtubule organising centres, DNA methylation patterns, cytoplasmic polarities, membranes and organelles, all of which were designed by natural selection. For example, chemical gradients in the zygote activate a small suite of embryonic genes, determining the basic organisation of the body (front and back, up and down, etc.). They must also carry intentional information. 'Information talk', once again, is equally applicable to nongenetic causal factors in development. Hence, like previous accounts of developmental information, Maynard Smith's teleosemantic account does not achieve its stated aim of generating a distinction between the role of genes in development and the roles of other causal factors (Griffiths, 2001, Shea, 2007). See also: Genes: Definition and Structure; Function and Teleology

\section{Extended Inheritance}

A traditional way to privilege genes over other causes in development is to argue that genes are the only things organisms inherit from their ancestors. Hence, the biological nature of organisms must be in the genes. DST insists on a principled definition of inheritance. Humans inherit half of their DNA from their mother, and half from their father. However, we also inherit an extended set of factors, limited by the number of reliably present resources that are 'passed on' and out of which a life cycle can be reconstructed. Some of these resources are familiar, such as chromosomes, nutrients, ambient temperatures and childcare. Others are less familiar, despite the recent explosion of work on epigenetic inheritance (Jablonka and Lamb, 2005). These unfamiliar ingredients include the chromatin-marking system that regulates gene expression, cytoplasmic chemical gradients and endosymbionts.

Epigenetic inheritance is the transmission of phenotypic variations to subsequent generations of cells or organisms that do not stem from changes in DNA base sequences (Jablonka and Raz, 2009). There are two senses of epigenetic inheritance: cellular epigenetic inheritance and broad epigenetic inheritance. 'Cellular epigenetic inheritance' refers to epigenetic transmission (either organism to organism, or cell to cell) of intracellular resources (organelles, DNA/histone modifications, feedback loops and membranes). This includes transmission of chromatin marks and RNAs (e.g. Wu and Morris, 2001), self-sustaining metabolic loops and chromatin inheritance in bacteria (Jablonka and Raz, 2009) and inheritance of alternative protein conformations such as prions (e.g. Uptain and Lindquist, 2002). Broad epigenetic inheritance is the transmission of nonmolecular features of the developmental system. This includes, but is not limited to, prenatal signals to the developing foetus (Gluckman and Hanson, 2004), parental effects generated through developmental interaction with offspring (e.g. Weaver et al., 2004), symbolic communication (Richerson and Boyd, 2005) and social learning (Avital and Jablonka, 2000). See also: Genomic Imprinting at the Transcriptional Level

'Niche construction' is an emerging area of biological research which draws attention to the importance of extended inheritance (Odling-Smee et al., 1996). However, developmental niche construction must be distinguished, at least conceptually, from ecological niche construction (Stotz, 2010). In ecological niche construction, organisms modify the selection pressures acting on their descendants by choosing or constructing the environments in which they and their descendants live. By this means they influence the direction of evolutionary change. For example, earthworms modify the soil to provide an aqueous niche. By doing this, earthworms have evolved very little since migrating to a terrestrial environment over 50 million years ago (Turner, 2000). In developmental niche construction, organisms structure the environment in which their descendants will develop, and thus exert environmental as well as genetic influences on the phenotypes of their descendants. Niche construction in this sense is the same thing as extended inheritance. The idea of developmental niche construction was independently suggested by developmental psychobiologists Meredith West and Andrew King (West and King, 1987) who developed the notion of the 'ontogenetic niche' to highlight the importance of the ecological and social legacies that are inherited alongside the zygote. This ontogenetic or developmental niche consists of all the resources that must be present in addition to the genome if a normal life cycle is to occur. See also: Ecological Development Biology; Life History Theory; Morphological Evolution: Epigenetic Mechanisms; Endosymbionts; Chromatin Remodelling and Histone Modification in Transcription Regulation; Sociobiology: A Philosophical Analysis

\section{Evolution}

'An animal is, in fact, a developmental system, and it is these systems, not the mere static adult forms which we conventionally take as typical of the species, which become modified in the course of evolution' (Waddington, 1953, p. 155).

DST expands the domain of evolutionary explanation. Evolution is not confined to changes in gene frequency, but encompasses changes in many classes of developmental resources. In the earliest stages of DST, one of Lehrman's primary targets was the idea that only 'innate' traits are explained by evolution, while 'acquired' traits must be explained by individual experience. The issue of whether a trait has an evolutionary explanation is quite separate from the issue of whether its development depends on specific features of the environment. As Lehrman argued,

Natural selection acts to select genomes that, in a normal developmental environment, will guide development into organisms with the relevant adaptive characteristics. But the path of development from the zygote stage to the 
phenotypic adult is devious, and includes many developmental processes, including, in some cases, various aspects of experience'. (Lehrman, 1970, p. 36)

The 'normal environment' to which Lehrman refers is the 'developmental niche' discussed in the previous section. The developmental niche is not merely somewhere that the genome finds itself. It is actively constructed through the activities of earlier generations, especially parents, and the activity of the developing organism itself (West and King, 1987). These activities, as well as the genes with which they interact, are products of evolution.

DST has been criticised for replacing the clear boundaries of an organism (but see Bouchard and Huneman, 2013) with the vague and indeterminate boundaries of a 'system'. This criticism seems less telling if we think of the system as a genome plus the developmental niche. It is uncontroversial that evolution did not simply design the genome and leave the rest to chance. The 'aspects of experience' to which Lehrman refers are also the result of evolutionary design - obvious examples include nests, breast milk and parental care. More broadly, all elements of the developmental niche that mediate adaptive parental effects must, by definition, have been designed by natural selection (Mousseau and Fox, 1998). However, the role of evolution in designing the niche goes beyond this. Nearly all mammals can synthesise ascorbic acid (vitamin C). So the presence of vitamin $\mathrm{C}$ in their physical environment is not part of their developmental niche. However, primates like ourselves evolved to replace endogenous production of vitamin C with environmental sources (Jukes and King, 1975), thus making that aspect of the environment part of the developmental system. While DST expands the developmental process to incorporate neglected elements of the developmental system, it limits those elements to those resources whose presence in each generation is necessary for the characteristics that are stably reproduced in the lineage.

Enthusiasts and sceptics about the evolutionary significance of extended inheritance often seem to agree that its significance depends on how reliably nongenetic factors are inherited across evolutionary time, and on thus how similar nongenetic resources are to genes (Jablonka and Raz, 2009). DST takes a rather different perspective. For DST, extended inheritance is simply one aspect of how developmental systems reproduce themselves. It is not important because it is a separate evolutionary process in which nongenetic factors evolve in a way that parallels genetic evolution. The primary reason that extended inheritance matters is because genetic and nongenetic factors evolve together as components of evolving developmental systems (Griffiths and Gray, 2004). It is uncontroversial to point out that when parents influence offspring phenotypes through nongenetic means, this must be included in a population genetic model, if that model is to make correct predictions about either phenotypic or genetic change (Wolf and Wade, 2009). So from the DST perspective, nongenetic heredity is not important because it mirrors genetic heredity. It is important because the mechanisms of heredity, whatever they are, affect the dynamics of evolution. See also: Developmental Evolution; Evolution of Development; Lorenz, Konrad Zacharias

\section{Criticisms of DST}

\section{Through its focus on causal interconnectedness DST makes actual causal analysis impossible}

If, in order to analyse development, one has to analyse the entire developmental system, DST would be doomed to failure by its own inclusiveness. However, DST takes a more strategic approach to complexity. As Oyama (2000b) has argued, DST does not render causal analysis impossible; on the contrary, it makes it more precise and more ample: more precise by discouraging overgeneralisations, more ample by broadening the scope of potentially significant developmental resources. Any investigation of complex phenomena requires a certain amount of 'black boxing'. Developmental systems theorists practice 'tactical' black boxing, in that it is always provisional and driven by pragmatic concerns.

\section{DST is 'armchair philosophy'}

This criticism seems to derive from a simple misunderstanding. Developmental systems theorists include philosophers, psychologists and biologists. They have often published in philosophy journals on the merits of DST. However, the disciplinary home of DST is not philosophy but biology and psychobiology (see Introduction). DST is not a philosophical offering to biology, but rather an attempt to abstract a theoretical framework from the work of a set of developmentally minded scientists (Griffiths and Gray, 2005).

\section{DST makes no specific predictions}

In a particularly strong attack on DST, Tooby et al. claim that 'developmental systems theory makes no specific predictions of any sort and thus is useless as a scientific theory' (Tooby et al., 2003, p. 860). This criticism may in part derive from the name 'developmental systems theory'. DST is not a 'theory' in the hypothetico-deductive sense. Rather, it is a biological framework (Godfrey-Smith, 2001). The fact that it makes no specific predictions is not a problem. The same could be said of evolutionary developmental biology, or of the 'genes-eye view'. However, like those other perspectives it does make general predictions: that development has no single locus of control, that the impact of any given cause is contingent upon the state of the system as a whole, that the notion of the 'genetic program' is of little heuristic value, that the study of heredity will benefit by an inclusive approach and that Lehrman's 'aspects of experience', as well as genes, can be explained by natural selection.

\section{References}

Avital E and Jablonka E (2000) Animal Traditions: Behavioural Inheritance in Evolution. Cambridge: Cambridge University Press. Bouchard F and Huneman P (2013) From Groups to Individuals: Evolution and Emerging Individuality. Cambridge and Massachusetts: MIT Press. 
Ford DH and Lerner RM (1992) Developmental Systems Theory: An integrative approach. Newbury Park, California: Sage.

Gluckman P and Hanson M (2004) The Fetal Matrix: Evolution, Development and Disease. Cambridge: Cambridge University Press.

Godfrey-Smith P (2001) On the status and explanatory structure of developmental systems theory. In: Oyama S, Griffiths PE and Gray RD (eds) Cycles of Contingency: Developmental Systems and Evolution, pp. 283-297. Cambridge and Massachusetts: MIT Press.

Gottlieb G (1970) Conceptions of prenatal behavior. In: Aronson LR, Tobach E, Lehrman DS and Rosenblatt JS (eds) Development and Evolution of Behavior: Essays in Memory of T. C. Schneirla, pp. 111-137. San Francisco: W. H. Freeman.

Gottlieb G (2001) A developmental psychobiological systems view: early formulation and current status. In: Oyama S, Griffiths PE and Gray RD (eds) Cycles of Contingency: Developmental Systems and Evolution, pp. 41-54. Cambridge and Massachusetts: MIT Press.

Griffiths PE (2001) Genetic information: a metaphor in search of a theory. Philosophy of Science 68 (3): 394-412.

Griffiths PE and Gray RD (1994) Developmental systems and evolutionary explanation. Journal of Philosophy XCI (6): 277-304.

Griffiths PE and Gray RD (2004) The developmental systems perspective: organism-environment systems as units of development and evolution. In: Massimo Pigliucci and Katherine Preston (eds) In Phenotypic Integration: Studying the Ecology and Evolution of Complex Phenotypes, pp. 409-431. Oxford and New York: Oxford University Press.

Griffiths PE and Gray RD (2005) Three ways to misunderstand developmental systems theory. Biology and Philosophy 20 (2): 417-425.

Griffiths PE and Knight RD (1998) What is the developmentalist challenge? Philosophy of Science 65 (2): 253-258.

Griffiths PE and Tabery JG (2013) Developmental systems theory: what does it explain, and how does it explain it? Advances in Child Development and Behavior 45: 65-94.

Griffiths PE (In Press) Proximate and ultimate information in biology. In: Couch M and Pfeiffer J (eds) Festschrifft for Philip Kitcher. New York and Oxford: Oxford University Press.

Hochman A (2012) The phylogeny fallacy and the ontogeny fallacy. Biology and Philosophy 28 (4): 593-612.

Jablonka E and Lamb MJ (2005) Evolution in Four Dimensions: Genetic, Epigenetic, Behavioral, and Symbolic Variation in the History of Life. Cambridge and Massachusetts: MIT press.

Jablonka E and Raz G (2009) Transgenerational epigenetic inheritance: prevalence, mechanisms, and implications for the study of heredity and evolution. The Quarterly Review of Biology 84 (2): 131-176.

Johnston TD (2001) Towards a systems view of development: an appraisal of Lehrman's critique of Lorenz. In: Oyama S, Griffiths PE and Gray RD (eds) Cycles of Contingency: Developmental Systems and Evolution, pp. 15-23. Cambridge and Massachusetts: MIT Press.

Jukes TH and King JL (1975) Evolutionary loss of ascorbic acid synthesizing ability. Journal of Human Evolution 4: 85-88.

Kitcher P (2001) Battling the undead: how (and how not) to resist genetic determinism. In: Singh R, Krimbas K, Paul D and Beatty J (eds) Thinking About Evolution: Historical, Philosophical and Political Perspectives (Festchrifft for Richard Lewontin), pp. 396-414. Cambridge: Cambridge University Press.
Kuo ZY (1922) How are our instincts acquired? Psychological Review 29: 344-365.

Lehrman DS (1953) Critique of Konrad Lorenz's theory of instinctive behavior. Quarterly Review of Biology 28 (4): 337-363.

Lehrman DS (1970) Semantic and conceptual issues in the nature-nurture problem. In: Lehrman DS (ed) Development and the Evolution of Behaviour, pp. 17-52. San Francisco: W. H. Freeman and Co..

Lickliter R and Berry TD (1990) The phylogeny fallacy: developmental psychology's misapplication of evolutionary theory. Developmental Review 10 (4): 348-364.

Linquist S, Machery E, Griffiths PE and Stotz K (2011) Exploring the folk biological conception of human nature. Philosophical Transactions of the Royal Society B 366: 444-453.

Maynard Smith J (2000) The concept of information in biology. Philosophy of Science 67 (2): 177-194.

Mayr E (1970) Populations, Species, and Evolution: An Abridgment of Animal Species and Evolution. Belknap: Press.

Moore CL (1992) The role of maternal stimulation in the development of sexual behavior and its neural basis. Annals of the New York Academy of Sciences 662: 160-177.

Mousseau TA and Fox CW (1998) Maternal Effects as Adaptations. Oxford and New York: Oxford University Press.

Odling-Smee FJ, Laland KN and Feldman MW (1996) Niche construction. American Naturalist 147 (4): 641-648.

Oyama S (1985) The Ontogeny of Information: Developmental Systems and evolution. Cambridge: Cambridge University Press.

Oyama S (2000a) The Ontogeny of Information: Developmental Systems and Evolution, 2nd edn. Durham, North Carolina: Duke University Press.

Oyama S (2000b) Causal democracy and causal contributions in developmental systems theory. Philosophy of Science 67: 332-347.

Richerson PJ and Boyd R (2005) Not by Genes Alone: How Culture Transformed Human Evolution. Chicago: University of Chicago Press.

Shea N (2007) Representation in the genome and in other inheritance systems. Biology and Philosophy 22 (3): 313-331.

Sterelny K and Griffiths PE (1999) Sex and Death: An Introduction to Philosophy of Biology. Chicago: University of Chicago Press.

Stotz K (2006) Molecular epigenesis: distributed specificity as a break in the central dogma. History and Philosophy of the Life Sciences 28 (4): 527-544.

Stotz K (2010) Human nature and cognitive-developmental niche construction. Phenomenology and the Cognitive Sciences 9 (4): 483-501.

Tooby J, Cosmides L and Barrett HC (2003) The second law of thermodynamics is the first law of psychology: evolutionary developmental psychology and the theory of tandem, coordinated inheritances: comment on Lickliter and Honeycutt. Psychological Bulletin 129 (6): 858.

Turner JS (2000) The Extended Organism: The Physiology of Animal-Built Structures. Cambridge, Massachusetts and London: Harvard University Press.

Uptain SM and Lindquist S (2002) Prions as protein-based genetic elements. Annual Review of Microbiology 56 (1): 703-741.

Waddington CH (1940) Organisers and Genes. Cambridge: Cambridge University Press.

Waddington CH (1952) The evolution of developmental systems. In: Herbert DA (ed) Proceedings of the Twenty-eighth Meeting of the Australian and New Zealand Association for the Advancement of 
Science, pp. 155-159. Brisbane, Australia: A.H Tucker, Government Printer.

Waddington CH (1953) The "Baldwin Effect", "Genetic Assimilation" and "Homeostasis". Evolution 7 (4): 386-387.

Waddington CH (2012[1942]) The epigenotype. International Journal of Epidemiology 41 (1): 10-13.

Waters CK (2007) Causes that make a difference. Journal of Philosophy 104 (11): 551-579.

Weber M (2006) The central dogma as a thesis of causal specificity. History and Philosophy of the Life Sciences 28 (4): 595-609.

Weaver ICG, Cervoni N, Champagne FA, et al. (2004) Epigenetic programming by maternal behavior. Nature Neuroscience 7 (8): $847-854$.

West MJ and King AP (1987) Settling nature and nurture into an ontogenetic niche. Developmental Psychobiology 20 (5): 549-562.

Wolf JB and Wade MJ (2009) What are maternal effects (and what are they not)? Philosophical Transactions of the Royal Society, B: Biological Sciences 364 (1520): 1107-1115.

Wu C and Morris J (2001) Genes, genetics, and epigenetics: a correspondence. Science 293 (5532): 1103-1105.

\section{Further Reading}

Bateson P and Gluckman P (2011) Plasticity, Robustness, Development and Evolution. Cambridge: Cambridge University Press.
Gissis S and Jablonka E (2011) The Transformations of Lamarckism: From Subtle Fluids to Molecular Biology. Cambridge: MIT Press. Griffiths P and Stotz K (2013) Genetics and Philosophy: An Introduction. Cambridge: Cambridge University Press.

Maestripieri D and Mateo JM (2009) Maternal Effects in Mammals. Chicago: The University of Chicago Press.

Michel GF and Moore CL (1995) Developmental Psychobiology: An Interdisciplinary Science. Cambridge: MIT Press.

Moore DS (2003) The Dependent Gene: The Fallacy of "Nature Vs. Nurture." New York: Henry Holt and Company.

Moore DS (2015) The Developing Genome: An Introduction to Behavioral Epigenetics. Oxford and New York: Oxford University Press.

Oyama S (2000c) Evolution's Eye: A Systems View of the Biology-Culture Divide. Durham, North Carolina: Duke University Press.

Robert JS (2004) Embryology, Epigenesis and Evolution: Taking Development Seriously. New York: Cambridge University Press. 